\title{
Scales of variation in the effects of limpets on rocky shores in the northwest Mediterranean
}

\author{
L. Benedetti-Cecchi*, F. Bulleri, S. Acunto, F. Cinelli \\ Dipartimento di Scienze dell'Uomo e dell'Ambiente, via A. Volta 6, 56126 Pisa, Italy
}

\begin{abstract}
Grazing is an important determinant of the spatial and temporal patterns of distribution of intertidal organisms on rocky shores. This process is likely to interact with other environmental factors at different scales in space and time. Understanding these interactions is important before generalizations about the ecological role of grazing can be advanced. In the present study, the ecological significance of grazing was evaluated by excluding limpets from mid-shore levels on rocky coasts in the northwest Mediterranean. Alternative models were evaluated leading to different predictions about the interactive effects of limpets, slope of the substratum and season. These models were distinguished on the basis of spatial and temporal consistency in these interactions. The null hypothesis of consistent effects of limpets was examined at relatively small (0.1 to $5 \mathrm{~km})$ and large $(100 \mathrm{~s}$ of $\mathrm{km}$ ) spatial scales, between seasons (summer vs winter), between dates within seasons, and in relation to slope of the substratum (horizontal vs vertical substrata). Univariate and multivariate analyses indicated inconsistencies in the effects of limpets at different spatial and temporal scales. Interactions between grazing, slope of the substratum and season changed from shore to shore, and strong effects of limpets were observed only occasionally. This variability is discussed in relation to differences in productivity and intensity of recruitment of algae among shores.
\end{abstract}

KEY WORDS: Algae - Limpets · Grazing · Rocky shores · Spatial scale $\cdot$ Temporal scale

\section{INTRODUCTION}

Natural populations fluctuate in abundance at varying scales in space and time. Identifying the scales at which variability occurs, and the processes that generate and maintain ecological heterogeneity, are among the major goals of ecology (Dayton \& Tegner 1984, Danielson 1991, Kolasa \& Pickett 1991, Wiens et al. 1993). Most of the past ecological research has focused on patterns and processes occurring at spatial scales of metres to hundreds of metres. Natural assemblages may exhibit drastic changes at these scales, both in terrestrial and aquatic systems, due to variability in biological interactions, recruitment and physical attributes of the habitat (e.g. Underwood \& Denley 1984,

\footnotetext{
*E-mail: bencecc@discat.unipi.it
}

Menge \& Sutherland 1987). These are also the spatial scales amenable to experimentation, and several studies have elucidated the roles of predation, grazing and competition in maintaining differences between or within habitats (Connell 1983, Schoener 1983, Sih et al. 1985, Huntly 1991). These analyses have been successful in explaining patterns of distribution of organisms at particular places and times, and have provided the basis for the development of general ecological concepts. All experiments are, however, scale- and context-dependent, and problems arise from generalizing the results of single experiments. The problem of context dependency is recognized explicitly in the ecological literature, but few studies have investigated variability in ecological processes at several spatial and temporal scales simultaneously so that the peril inherent in scaling-up from the small to the large can be evaluated formally (Underwood \& Petraitis 1993). 
Grazing is one of the major biological processes in terrestrial and aquatic systems. In rocky intertidal habitats, invertebrate grazers, such as limpets and snails, may have a profound influence on patterns of abundance and distribution of intertidal organisms through direct as well as indirect effects (Lubchenco \& Gaines 1981, Hawkins \& Hartnoll 1983, Sousa 1985, Menge 1995, Benedetti-Cecchi 2000). Although inferences about large-scale effects of grazing have been made, including contrasts between different geographical regions (Gaines \& Lubchenco 1982, Dethier \& Duggins 1988), and sheltered versus exposed shores (Lubchenco \& Menge 1978, Hawkins et al. 1992), most experimental analyses focused on small-scale spatial patterns (reviewed in Underwood 1985). This was justified by the fact that the foraging behaviour and patterns of movement of grazing gastropods are themselves influenced by small-scale features of the habitat, such as general aspect of the substratum, presence of predators and availability of refuges, and changes in physical conditions associated with height on the shore (Chapman \& Underwood 1992). Thus, experiments investigating the influence of grazing on intertidal assemblages generally require high spatial resolution (sensu Schneider 1994).

In addition to responding to local features of the habitat, patterns of activity of grazers on rocky shores are also likely to interact with ecological processes that operate at larger scales. Populations of grazing gastropods are known to change in abundance from place to place and time to time in relation to variability in recruitment and mortality (Underwood 1979, Branch 1981). The impact of grazers on intertidal assemblages is directly related to the size of the grazer populations, but it may also depend on the timing and intensity of recruitment of algae or other organisms, such as barnacles, events that may themselves be spatially and temporally variable (Underwood et al. 1983, Farrell 1991, Benedetti-Cecchi 2000). Therefore, differences in the general physical and biological settings of the habitat, and seasonal or other temporal changes in patterns of foraging of grazers and in the recruitment of the target populations are all likely to influence the relative importance of grazing at varying scales in space and time. These issues can only be addressed by increasing the extent and scope of experimental investigations about grazing.

In this study we investigated the long-term effects of limpets at different spatial and temporal scales on rocky coasts in the northwest Mediterranean. Knowledge of the effects of environmental factors on the foraging activity of limpets and how grazing affects assemblages is limited for these rocky shores, so that specific predictions about these interactions are difficult to make. Some general models can, however, be proposed on the basis of the evidence obtained from other studies (see above). In a system like the Mediterranean, characterized by narrow tidal ranges (35 to $40 \mathrm{~cm}$ ), desiccation may limit the growth of algae on vertical substrata compared to flat surfaces, where physical stress is reduced due to the retention of sea water. This model predicts that limpets have a larger effect on algae on horizontal than vertical substrata, while physical factors are more important on vertical surfaces. These patterns are also likely to be more important in the summer, during prolonged periods of calm seas and high temperatures.

Alternatively, the aspect of the substratum might be more important in regulating the behaviour and foraging activity of limpets than in influencing the establishment of algae. For example, vertical substrata usually provide better physical conditions (more shade and lower temperatures) for limpets than horizontal surfaces (Garrity 1984, Williams \& Morritt 1995). If this is the case, excluding limpets from vertical substrata should result in larger effects on algae than excluding limpets from flat surfaces. This difference may be less pronounced during the winter, when physical stress on flat substrata should be reduced in comparison to the summer season.

The 2 models above predict interactive effects of limpets, slope of the substratum and season that are consistent in space and time. As a third alternative, these interactions may change from place to place and time to time in relation to other physical and biological processes such as storms or recruitment. To distinguish among these models, we experimentally excluded limpets at sites of different slope (nearly horizontal vs vertical), at 2 different scales in space and time. Two replicate sites for each slope were established in each of 2 different seasons (summer and winter) and on 2 dates within each season on 3 shores. Sites on each shore were 0.1 to $5 \mathrm{~km}$ apart, while shores were $100 \mathrm{~s}$ of $\mathrm{km}$ apart.

\section{METHODS}

Study sites and organisms. The study was performed at 3 localities in the northwest Mediterranean: Baratti $\left(42^{\circ} 57^{\prime} \mathrm{N}, 10^{\circ} 30^{\prime} \mathrm{E}\right)$, Capraia $\left(43^{\circ} 02^{\prime} \mathrm{N}, 9^{\circ} 50^{\prime} \mathrm{E}\right)$, and Punta Bianca $\left(44^{\circ} 02^{\prime} \mathrm{N}, 9^{\circ} 58^{\prime} \mathrm{E}\right)$. Capraia is an island, while the other localities are on the mainland. Only the rocky coast on the west side of Capraia was used for the experiments, to be consistent with the geographical orientation of the locations on the mainland. These localities represented 1 of several possible sets of shores that might have been chosen to test whether the effects of limpets are general at scales of hundreds of kilometres in the northwest Mediterranean. The 
relevant criterion used to select the locations was that they should have qualitatively similar assemblages of barnacles, limpets, encrusting algae and erect algae.

Assemblages at mid-shore levels were represented mainly by the foliose alga Rissoella verruculosa (Bertolini) J. Agardh, by filamentous algae such as Chaetomorpha aerea (Dillwyin) Kützing and Polysiphonia spp., by encrusting red algae (probably the encrusting base of Corallina elongata Ellis et Solander) and the brown crust Ralfsia verrucosa (Areschoug) J. Agardh, and by the barnacles Chthamalus montagui Southward and C. stellatus (Poli). The most common grazers were the limpets Patella aspera Roding, P. caerulea Linné and $P$. rustica Linné. Further descriptions of mid-shore assemblages in the northwest Mediterranean can be found in Benedetti-Cecchi \& Cinelli (1993, 1997), Menconi et al. (1999), Benedetti-Cecchi (2000) and Benedetti-Cecchi et al. (2000).

Experimental design. The experiments were initiated independently on each shore on 2 dates during summer 1996 and on 2 dates in winter 1997. Dates were randomly assigned to shores in each particular season. At each date on a particular shore, 2 nearly horizontal (slope $<20^{\circ}$ ) and 2 nearly vertical (slope $>60^{\circ}$ ) sites were established, where a site was a stretch of coastline of 10 to $20 \mathrm{~m}$. Vertical and horizontal sites were selected randomly at the beginning of the experiment and were interspersed along approximately $5 \mathrm{~km}$ on each shore. Thus, there was a total of 48 sites in this experiment $(3$ shores $\times 2$ seasons $\times 2$ dates $\times 2$ slopes $\times 2$ sites), which started in June 1996 and lasted until November 1998.

Nine $17 \times 17 \mathrm{~cm}$ plots were haphazardly marked with pieces of epoxy-putty (Subcoat S, Veneziani) at mid-shore levels in areas generally occupied by barnacles and limpets and with no or only minor cover $(<10 \%)$ of erect algae. Three plots with limpets were randomly assigned to each of the following treatments: control plots (marked and not further disturbed); enclosures (plots where limpets were included at natural densities); exclosures (plots from which limpets were removed). Limpets were excluded/included using fences constructed with a plastic mesh reinforced with a mesh of galvanized iron. These devices were $17 \times 17$ $\times 4 \mathrm{~cm}$ in size (mesh size of $0.5 \times 0.5 \mathrm{~cm}$ ), and were anchored to the substratum with stainless-steel screws inserted into rawl-plugs in the rock. Although these devices were flexible enough to follow the rugosity of the substratum, epoxy-putty was used to bolt the corners of the fences to the rock and to fill gaps between them and the substratum. Enclosures provided procedural controls for artifacts due to these devices (e.g. Anderson \& Underwood 1997). As a further control for artifacts, we also established partial fences, but only on horizontal substrata (3 replicate plots in each site). A partial fence consisted of 4 angles placed at the corners of the plot, so that a gap about $8 \mathrm{~cm}$ wide occurred in the middle of each side of the quadrat. Although we did not control for potential effects of enclosures on the foraging activity of limpets (and possible indirect effects on the rest of the assemblage), enclosures were apparently more effective in detecting artifacts than partial fences (Benedetti-Cecchi et al. unpubl. data), so that only results from enclosures are presented here. The experimental sites were visited approximately every 2 mo during the experiment. At each visit, damaged fences (including those that showed signs of oxidation) were replaced and the density and size of limpets in enclosures were adjusted to match densities and sizes found in the controls. Some limpets reinvaded the exclosure plots. These were generally small individuals that were removed by hand.

Sampling and statistical analyses. Plots were sampled 4 times (every 2 to $3 \mathrm{mo}$ ) for the first year of the experiment, and a final sample was collected $1.5 \mathrm{yr}$ after the start. Sampling after $1.5 \mathrm{yr}$ confounded the effects due to time when the experiment was set up with patterns occurring when the plots were monitored (the experiments begun in summer were sampled in winter and the experiments begun in winter were sampled in summer). There was, however, no problem in distinguishing among the models proposed above, since there were no consistent seasonal effects in our study (see 'Results'). We use these data to examine the long-term effects of limpets on this assemblage in relation to the life-histories and biology of the relevant taxa (Benedetti-Cecchi \& Cinelli 1993, Menconi et al. 1999, Benedetti-Cecchi 2000). The percentage cover of algae was assessed in areas of $10 \times 10 \mathrm{~cm}$ in the middle of the experimental plots. Estimates of percentage cover were obtained as intersections using a metal frame with a grid of 64 points. Densities of limpets were estimated by counting the individuals present in whole plots.

Univariate and multivariate procedures were used to test hypotheses about consistency of the effects of limpets over space and time. A 6-factor mixed-model analysis of variance (ANOVA) was used for univariate tests. The factors were: shore (random and orthogonal), season (fixed and orthogonal), date (random and nested within each combination of shore $\times$ season), slope (fixed and orthogonal), site (random and nested within each combination of slope $\times$ date [shore $\times$ season]), and limpets (fixed and orthogonal). All data were transformed to natural logarithms to homogenize variances (after Cochran's C-test). When necessary, StudentNewman-Keuls (SNK) tests were used for post-hoc comparisons of the means estimated by the ANOVA.

Multivariate analyses were carried out to compare assemblages among treatments, separately for each 
season, shore and slope of the substratum. A matrix of similarity between each pair of samples was calculated using the Bray-Curtis coefficient (Bray \& Curtis 1957) on fourth-root-transformed data (Clarke 1993). This transformation was used to reduce differences in scale among variables, while preserving information about relative abundance of species among samples. Nonmetric multidimensional scaling (nMDS) was used to produce 2-dimensional plots of the rank orders of similarities among samples in the different treatments (Field et al. 1982, Clarke 1993, Anderson \& Underwood 1997). The variables included in these analyses consisted of several taxa of algae (see Menconi et al. 1999), barnacles and mussels. Invertebrates were also included in these analyses since they might have been affected by the manipulation of limpets directly (e.g. Dayton 1971), and indirectly through changes in the abundance of algae (Petraitis 1990, Anderson \& Underwood 1997, Benedetti-Cecchi 2000).

\section{Limpets}

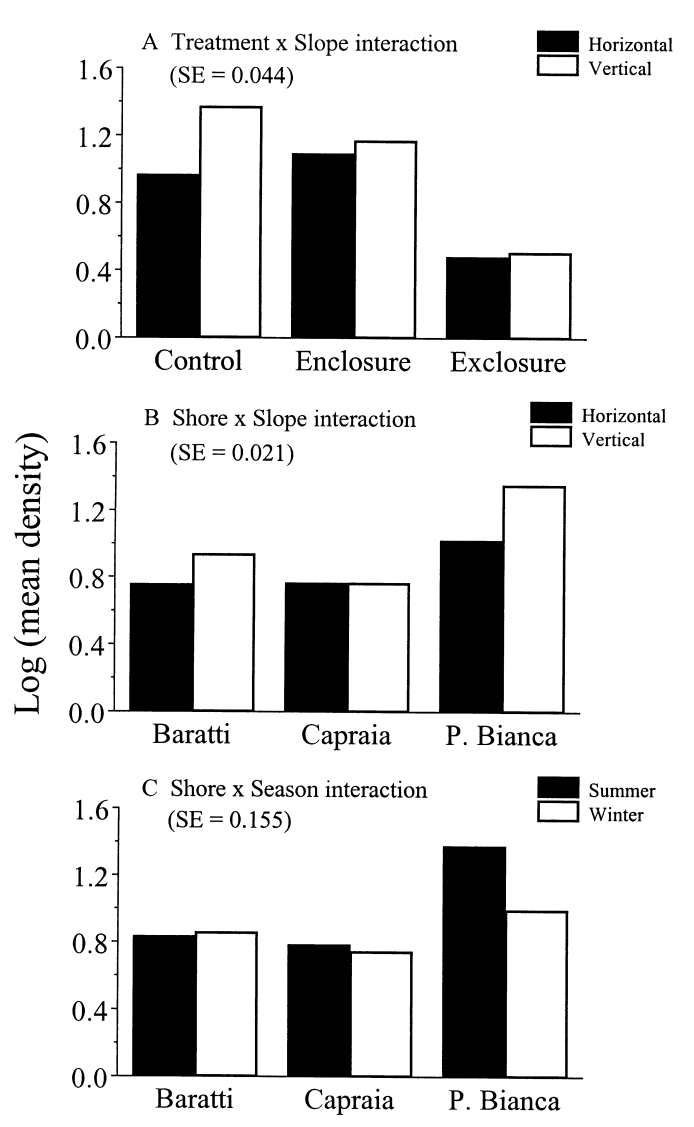

Fig. 1. Interaction plots for (A) treatment $x$ slope, (B) shore $\times$ slope, and $(C)$ shore $\times$ season effects from the analysis of variance on the mean abundance of limpets. Standard errors for comparisons of the means are given in parentheses in each plot

\section{RESULTS}

Fences were effective in excluding limpets of medium to large size (10 to $20 \mathrm{~mm}$ ) during the study period. However, small limpets $(<7 \mathrm{~mm})$ tended to reinvade the exclosure plots, particularly by the end of the study, and total exclusion was not achieved. The mean number of limpets found in each treatment (averaged across 5 sampling occasions) was analyzed using ANOVA to test for possible artifacts due to using fences, and to compare patterns of abundance of limpets across scales in space and time. These analyses indicated that there were significantly fewer limpets in exclosures than in each of the other treatments, and that enclosures and controls had similar numbers of limpets on horizontal, but not on vertical substrata, where limpets were particularly abundant (Fig. 1A). These patterns resulted in a significant treatment $x$ slope interaction (Table 1 and results from SNK tests). There were significantly more limpets on vertical than horizontal substrata in unmanipulated plots, but slope had no effect on the number of limpets present in each of the other treatments (Fig. 1A; SNK tests). Thus, the treatment $\times$ slope interaction resulted from the larger number of limpets in controls on vertical substrata and not from the effectiveness of excluding limpets differing between slopes.

Differences between slopes in the mean number of limpets were not consistent from shore to shore, resulting in a significant shore $\times$ slope interaction (Table 1 ). Vertical substrata had more limpets than horizontal substrata at Baratti and Punta Bianca, but not at Capraia (Fig. 1B; SNK tests). The analysis also detected a significant shore $\times$ season interaction, with significantly more limpets in plots established in summer than winter at Punta Bianca, and no difference between seasons on the other shores (Fig. 1C, Table 1; and SNK tests). In addition to the large variability at the scale of the shore (in interaction with other factors), the mean number of limpets was also highly variable at small spatial scales, as indicated by the significant differences among sites in the analysis (Table 1).

Limpets decreased the abundance of coarsely branched algae, but this effect was very variable as indicated by the significant limpets $\times$ slope $\times$ date (shore $\times$ season) and limpets $\times$ shore interactions (Table 2). Only at Baratti did limpets influence the abundance of these plants, but effects were variable and changed with inclination of the substratum and among dates (Fig. 2). There was a significant effect of limpets on horizontal but not on vertical substrata for both the summer- and winter-initiated experiments on the first date, while on the second date grazing was significant irrespective of slope in treatments initiated in summer, and only on vertical substrata for those ini- 
Table 1. ANOVA on densities of limpets averaged over 5 sampling occasions in each treatment. Tests of factors involved in higher-order interactions are not interpreted because there are no hypotheses related to them (Underwood 1997). Probabilities of relevant tests are indicated in bold

\begin{tabular}{|c|c|c|c|c|c|}
\hline Source of variation & $\mathrm{df}$ & MS & $F$ & $\mathrm{p}$ & $F$-ratio versus \\
\hline Shore & 2 & 7.1906 & 98.4 & $<0.001$ & Date $($ Shore $\times$ Season) \\
\hline Season & 1 & 1.9009 & 1.1 & $>0.4$ & Shore $\times$ Season \\
\hline Shore $\times$ Season & 2 & 1.7352 & 23.7 & $<0.002$ & Date (Shore × Season) \\
\hline Date (Shore $\times$ Season) & 6 & 0.0731 & 0.2 & $>0.9$ & Site $($ Slope $\times$ Date $[$ Shore $\times$ Season] $)$ \\
\hline Slope & 1 & 3.1288 & 3.2 & $>0.2$ & Shore $\times$ Slope \\
\hline Shore $\times$ Slope & 2 & 0.9883 & 6.1 & $<0.05$ & Slope $\times$ Date $($ Shore $\times$ Season $)$ \\
\hline Season $\times$ Slope & 1 & 0.7000 & 14.3 & $>0.5$ & Shore $\times$ Season $\times$ Slope \\
\hline Shore $\times$ Season $\times$ Slope & 2 & 0.0491 & 0.3 & $>0.7$ & Slope $\times$ Date $($ Shore $\times$ Season $)$ \\
\hline Slope $\times$ Date $($ Shore $\times$ Season) & 6 & 0.1609 & 0.4 & $>0.8$ & Site $($ Slope $\times$ Date $[$ Shore $\times$ Season] $)$ \\
\hline Site $($ Slope $\times$ Date $[$ Shore $\times$ Season] & 24 & 0.3906 & 3.0 & $<0.001$ & Residual \\
\hline Treatment & 2 & 20.5913 & 60.2 & $<0.002$ & Treatment $\times$ Shore \\
\hline Treatment $\times$ Shore & 4 & 0.3423 & 2.3 & $>0.1$ & Treatment $\times$ Date $($ Shore $\times$ Season $)$ \\
\hline Treatment $\times$ Season & 2 & 0.1156 & 0.5 & $>0.6$ & Treatment $\times$ Shore $\times$ Season \\
\hline Treatment $\times$ Slope & 2 & 1.5140 & 10.8 & $<0.05$ & Treatment $\times$ Shore $\times$ Slope \\
\hline Treatment $\times$ Shore $\times$ Season & 4 & 0.2456 & 1.7 & $>0.2$ & Treatment $\times$ Date $($ Shore $\times$ Season) \\
\hline Treatment $\times$ Shore $\times$ Slope & 4 & 0.1404 & 0.9 & $>0.4$ & Treatment $\times$ Slope $\times$ Date $($ Shore $\times$ Season $)$ \\
\hline Treatment $\times$ Season $\times$ Slope & 2 & 0.1940 & 0.5 & $>0.6$ & Treatment $\times$ Shore $\times$ Season $\times$ Slope \\
\hline Treatment $\times$ Shore $\times$ Season $\times$ Slope & 4 & 0.3628 & 2.3 & $>0.1$ & Treatment $\times$ Slope $\times$ Date $($ Shore $\times$ Season $)$ \\
\hline Treatment $\times$ Date $($ Shore $\times$ Season) & 12 & 0.1464 & 1.3 & $>0.2$ & Treatment $\times$ Site (Slope $\times$ Date $[$ Shore $\times$ Season $]$ \\
\hline Treatment $\times$ Slope $\times$ Date $($ Shore $\times$ Season $)$ & 12 & 0.1558 & 1.4 & $>0.2$ & Treatment $\times$ Site (Slope $\times$ Date $[$ Shore $\times$ Season] \\
\hline Treatment $\times$ Site $($ Slope $\times$ Date $[$ Shore $\times$ Season $])$ & 48 & 0.1115 & 0.9 & $>0.7$ & Residual \\
\hline Residual & 288 & 0.1283 & & & \\
\hline Total & 431 & & & & \\
\hline
\end{tabular}

Table 2. ANOVAs on mean percentage cover of algae after $1.5 \mathrm{yr}$ from start of the experiment. F-ratios calculated as in Table 1 (with Limpets replacing Treatment). Tests of factors involved in higher order interactions are not interpreted because there are no hypotheses related to them (Underwood 1997). Pooling procedures have been used according to Winer et al. (1991) and Underwood (1997). Probabilities of relevant tests are indicated in bold

\begin{tabular}{|c|c|c|c|c|c|c|c|c|c|c|}
\hline \multirow[t]{2}{*}{ Source of variation } & \multirow[t]{2}{*}{ df } & \multicolumn{3}{|c|}{ Coarsely branched algae } & \multicolumn{3}{|c|}{ Encrusting algae } & \multicolumn{3}{|c|}{ Filamentous algae } \\
\hline & & MS & $F$ & $\mathrm{p}$ & MS & $F$ & $\mathrm{p}$ & MS & $F$ & $\mathrm{p}$ \\
\hline Shore & 2 & 20.29 & 110.7 & $<0.001$ & 128.10 & 15.2 & $<0.001$ & 38.76 & 4.4 & $>0.05$ \\
\hline Season & 1 & 35.60 & 1.8 & $>0.3$ & 3.58 & 0.2 & $>0.65$ & 11.09 & 0.1 & $>0.75$ \\
\hline Shore $\times$ Season & 2 & 19.70 & 107.5 & $<0.001$ & 17.69 & 2.1 & $>0.2$ & 102.64 & 11.7 & $<0.01$ \\
\hline Date (Shore $\times$ Season) & 6 & 0.18 & 0.1 & $>0.9$ & 8.45 & 2.2 & $>0.05$ & 8.80 & 2.2 & $>0.05$ \\
\hline Slope & 1 & 26.61 & 4.0 & $>0.15$ & 0.20 & 0.1 & $>0.8$ & 78.96 & 24.6 & $<0.05$ \\
\hline Shore $\times$ Slope & 2 & 6.59 & 3.7 & $>0.05$ & 3.22 & 1.9 & $>0.2$ & 3.21 & 0.6 & $>0.5$ \\
\hline Season $\times$ Slope & 1 & 14.55 & 2.6 & $>0.2$ & 0.92 & 0.2 & $>0.7$ & 2.19 & 165.1 & $<0.01$ \\
\hline Shore $\times$ Season $\times$ Slope & 2 & 5.57 & 3.3 & $>0.1$ & 5.33 & 3.1 & $>0.1$ & 0.01 & 0.0 & $>0.9$ \\
\hline Slope $\times$ Date $($ Shore $\times$ Season) & 6 & 1.78 & 1.1 & $>0.35$ & 1.73 & 0.4 & $>0.8$ & 5.34 & 1.3 & $>0.25$ \\
\hline Site $($ Slope $\times$ Date $[$ Shore $\times$ Season] $)$ & 24 & 1.62 & 1.9 & $<0.01$ & 3.85 & 2.3 & $<0.001$ & 4.01 & 2.0 & $<0.01$ \\
\hline Limpets & 2 & 7.12 & 3.4 & $>0.1$ & 3.76 & 0.5 & $>0.6$ & 20.91 & 14.2 & $<0.05$ \\
\hline Limpets $\times$ Shore & 4 & $2.10^{\mathrm{a}}$ & 2.4 & $<0.05$ & 7.76 & 4.5 & $<0.05$ & 1.48 & 2.9 & $>0.05$ \\
\hline Limpets $\times$ Season & 2 & 1.11 & 1.3 & $>0.3$ & 0.09 & 0.0 & $>0.9$ & 5.25 & 1.5 & $>0.3$ \\
\hline Limpets $\times$ Slope & 2 & 1.10 & 1.6 & $>0.3$ & 5.04 & 24.1 & $<0.01$ & 3.85 & 12.0 & $<0.05$ \\
\hline Limpets $\times$ Shore $\times$ Season & 4 & 0.83 & 0.9 & $>0.4$ & 3.29 & 1.9 & $>0.15$ & 3.49 & 6.9 & $<0.01$ \\
\hline Limpets $\times$ Shore $\times$ Slope & 4 & 0.69 & 0.4 & $>0.7$ & 0.21 & 0.1 & $>0.9$ & 0.32 & 0.3 & $>0.8$ \\
\hline Limpets $\times$ Season $\times$ Slope & 2 & 0.34 & 0.8 & $>0.5$ & 3.28 & 3.6 & $>0.5$ & 0.95 & 1.8 & $>0.25$ \\
\hline Limpets $\times$ Shore $\times$ Season $\times$ Slope & 4 & 0.41 & 0.3 & $>0.8$ & 5.29 & 3.3 & $<0.05$ & 0.52 & 0.5 & $>0.7$ \\
\hline Limpets $\times$ Date $($ Shore $\times$ Season $)$ & 12 & 0.93 & 1.1 & $>0.4$ & 1.71 & 1.5 & $>0.15$ & 0.51 & 0.2 & $>0.9$ \\
\hline Limpets $\times$ Slope $\times$ Date $($ Shore $\times$ Season $)$ & 12 & $1.58^{\mathrm{b}}$ & 1.9 & $<0.05$ & 1.58 & 1.3 & $>0.2$ & 0.99 & 0.4 & $>0.9$ \\
\hline Limpets $\times$ Site $($ Slope $\times$ Date $[$ Shore $\times$ Season $])$ & 48 & 0.87 & 1.0 & $>0.4$ & 1.18 & 0.7 & $>0.9$ & 2.27 & 1.2 & $>0.2$ \\
\hline Residual & 288 & 0.85 & 1.68 & & & 1.97 & & & & \\
\hline Total & 431 & & & & & & & & & \\
\hline
\end{tabular}




\section{Coarsely branched algae}
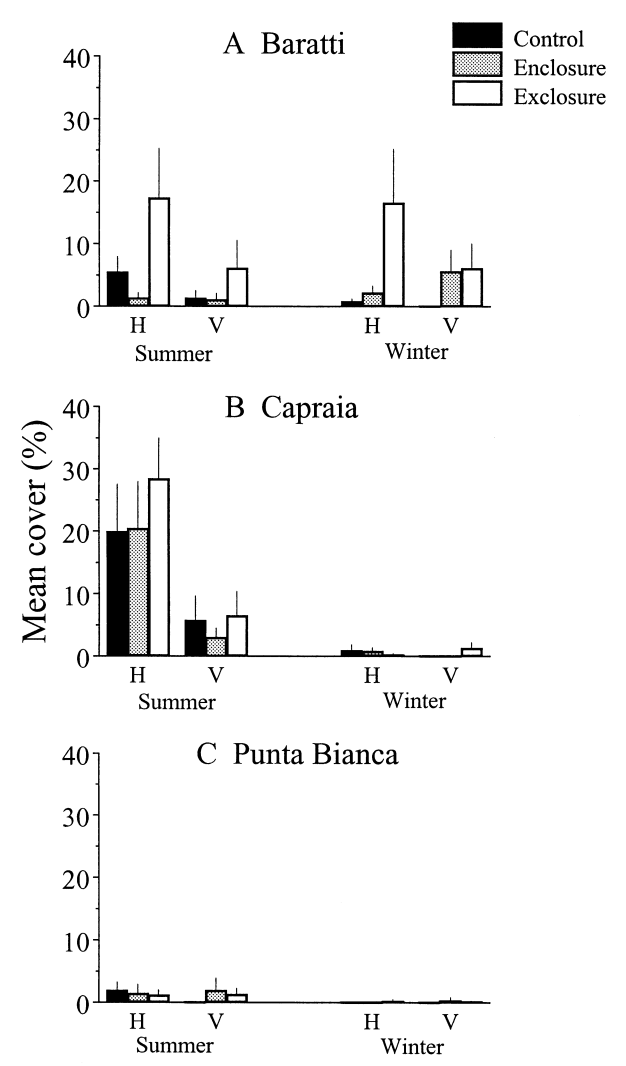

Fig. 2. Effects of limpets on mean percentage cover $(+\mathrm{SE}, \mathrm{n}=$ 12) of coarsely branched algae in relation to season and slope (H: horizontal; V: vertical) of the substratum on 3 shores. Data pooled across sites and dates

tiated in winter (SNK tests). Coarsely branched algae were more abundant in plots established in summer at Capraia, while no difference between seasons was observed on the other shores, resulting in a significant shore $\times$ season interaction (Table 2; SNK tests). Finally, small-scale spatial variability was large for the coarsely branched algae, as indicated by the significant effect of site (Table 2).

The cover of encrusting coralline algae decreased at Baratti when limpets were excluded from horizontal substrata in the summer, whereas on vertical substrata the lowest cover was observed in enclosures, possibly indicating artifacts due to the fences; artifacts might have occurred in treatments initiated in winter as well at Baratti (Fig. 3). Limpets exerted some negative effects on encrusting coralline algae at Punta Bianca, and no effects at Capraia. These patterns resulted in a significant limpets $\times$ shore $\times$ season $\times$ slope interaction (Table 2), but the SNK test could discriminate among treatments only for the summer start at Punta Bianca on vertical substrata, producing the following ranking of the means: exclosure $>$ enclosure $=$ control. Exclud- ing limpets had no effects on horizontal substrata. Small-scale spatial variation was important also for the encrusting coralline algae, as indicated by the significant effect of site in the analysis (Table 2).

The effects of limpets on filamentous algae were spatially and temporally variable, and also changed with slope of the substratum, as indicated by the significant limpets $\times$ shore $\times$ season and limpets $\times$ slope interactions (Fig. 4, Table 2). SNK tests within each combination of shore and season indicated that exclosure plots had significantly more filamentous algae than the other treatments at Baratti and Capraia for treatments initiated in winter (exclosure > enclosure > control on both shores), but not in summer, when treatments did not differ significantly; there was no significant effect of grazing at Punta Bianca. The exclusion of limpets increased the percentage cover of the filamentous algae on both horizontal and vertical substrata. The following ranking of the means resulted from the SNK test on horizontal surfaces: exclosure $>$ control $>$ enclosure. The ranking on vertical substrata was: exclosure $>$ enclosure $>$ control, indicating that fences increased the abundance of the filamentous algae in

Encrusting coralline algae
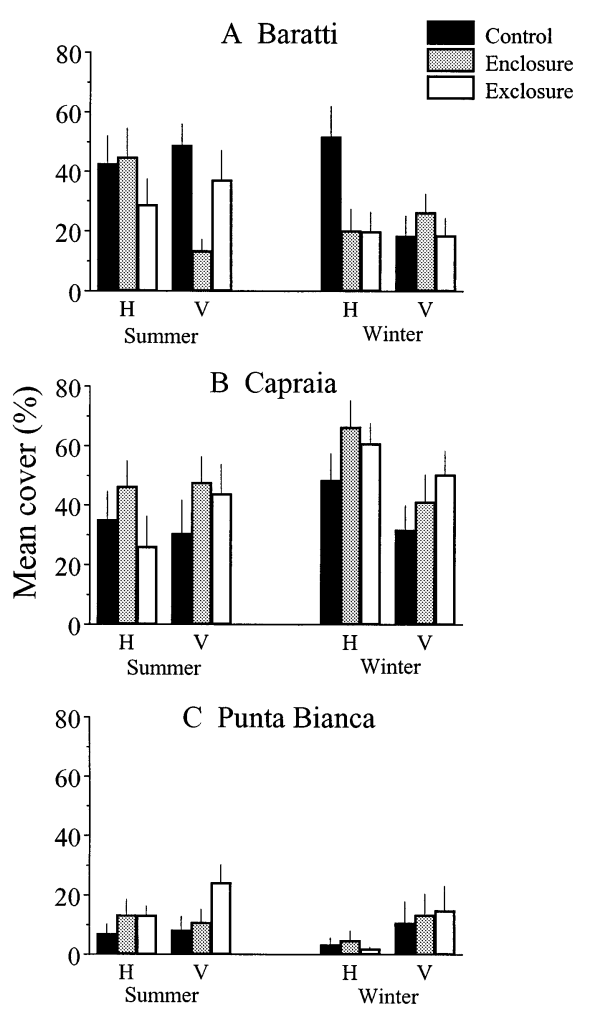

Fig. 3. Effects of limpets on mean percentage cover $(+\mathrm{SE}, \mathrm{n}=$ 12) of encrusting coralline algae in relation to season and slope of the substratum on 3 shores. Data pooled across sites and dates 
Filamentous algae
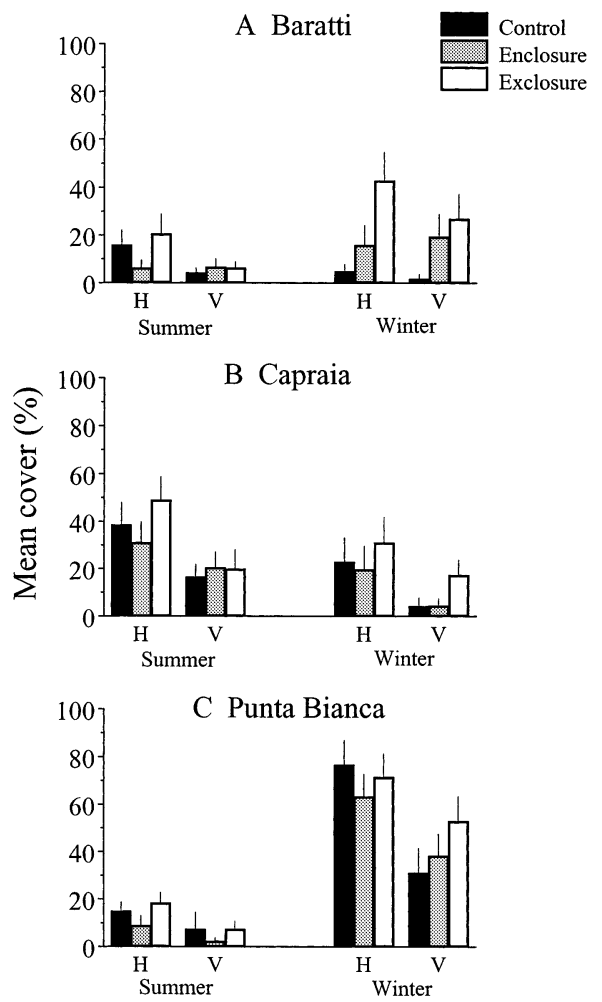

Fig. 4. Effects of limpets on mean percentage cover $(+\mathrm{SE}, \mathrm{n}=$ 12) of filamentous algae in relation to season and slope of the substratum on 3 shores. Data pooled across sites and dates

this habitat. Although percentage cover was significantly larger on horizontal surfaces irrespective of the treatment considered (from SNK tests comparing slopes in each treatment), limpets accounted for about $38 \%$ of the differences between vertical and horizontal substrata when only fenced plots were compared. There were also differences between seasons and slopes that were independent of any effect of limpets. There were consistently more filamentous algae on horizontal than vertical substrata and in plots initiated in winter than in those initiated during the summer, but differences between seasons were larger on vertical substrata, resulting in a significant season $\times$ slope interaction (Table 2, Fig. 4). Finally, there were large and significant differences among sites (Table 2).

Only the nMDS ordinations comparing treatments initiated in winter, independently for each shore and slope of the substratum, are presented and interpreted here (Fig. 5). Those relative to the summer starts had stress values $>0.2$, which is considered a threshold value for an interpretable nMDS (Field et al. 1982, Clarke 1993). The ordination separated most of the exclosure plots from the other treatments on vertical substrata of Baratti and Capraia, although there was considerable variation among plots within any treatment (Fig. 5A,B). Separation of some exclosure plots also occurred on horizontal surfaces at Baratti, while no effect of limpets was evident at Punta Bianca (Fig. 5C). The large stress values of these analyses suggest caution in the interpretation of the results.

\section{DISCUSSION}

There was considerable variation in the effects of limpets on rocky shores in the northwest Mediterranean. None of the models predicting consistent interactions among limpets, slope of the substratum and season were supported by the data. The importance of grazing changed in relation to the inclination of the substratum, but these effects were spatially and temporally variable. Most of the variability occurred at large spatial scales (i.e. from shore to shore). The relationship between grazing and slope of the substratum

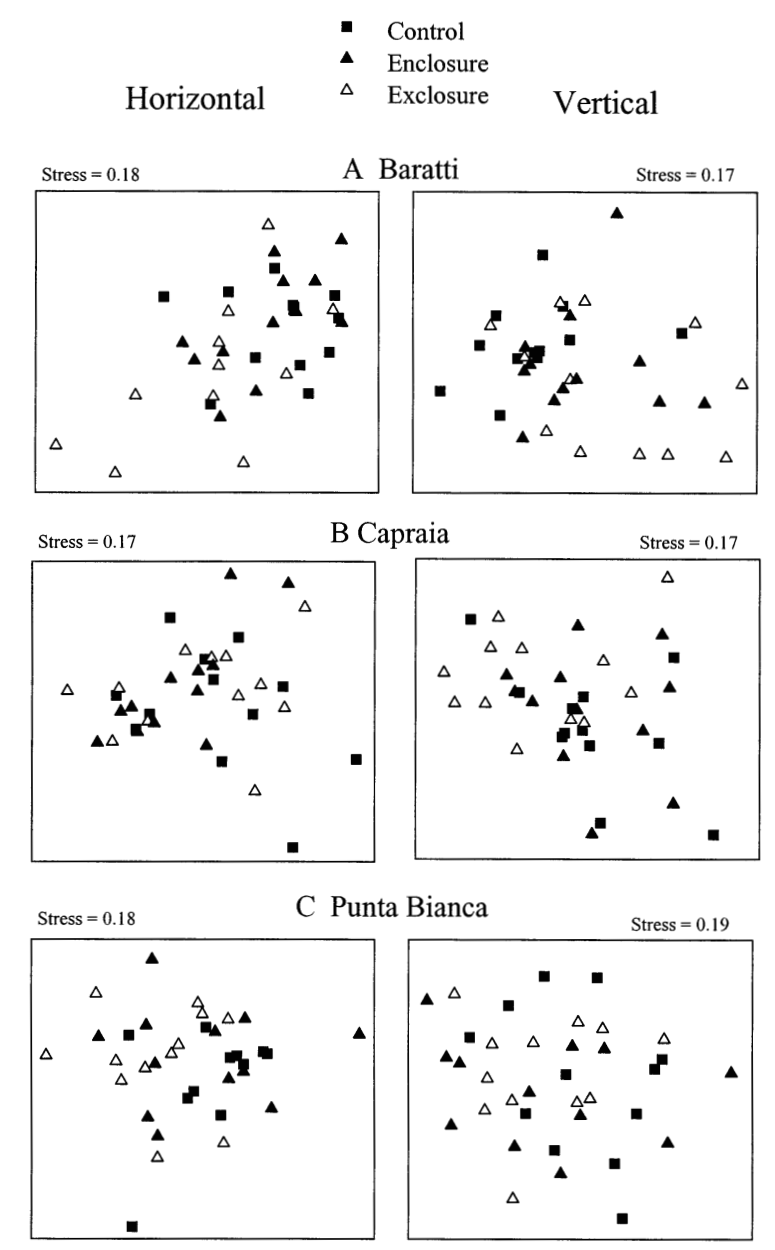

Fig. 5. nMDS ordination plots comparing assemblages in treatments initiated in winter on horizontal and vertical substrata for each shore separately 
depended on the particular shore and date or season considered. Similarly, the relationship between grazing and season was not consistent across shores. Despite this variability, significant effects of limpets were observed more frequently at Baratti and less frequently at Punta Bianca, with Capraia intermediate between the two. It is known from previous studies that small limpets have no effects on these assemblages (Benedetti-Cecchi 2000), so it is unlikely that reinvasion of some exclosure plots by limpets $<7 \mathrm{~mm}$ in length can explain the large amount of variation in grazing documented here.

Several factors may account for the patterns of interaction at large spatial scales observed in this study, including variability in recruitment of algae (BenedettiCecchi et al. unpubl. data), variability in patterns of distribution and abundance of limpets and differences in other environmental factors. In particular, the effects of limpets at Punta Bianca might have been counteracted by events of intense recruitment of algae. It is well known that under benign physical conditions macroalgae may proliferate and usurp space from grazing invertebrates such as limpets, so that the relationship between these organisms shifts from a trophic interaction to a competitive one (Underwood \& Jernakoff 1981). These processes can be expected to occur in areas with high availability of nutrients, where the growth of algae is not limited by physical factors such as desiccation or other types of stress, and where grazers are small in size. Bottom-up effects (Menge 1992, Power 1992, Carpenter et al. 1995) were probably important at Punta Bianca, where physical conditions could differ from those occurring on the other shores. Punta Bianca is located in the Ligurian Sea, one of the most productive areas of the Mediterranean, with high concentrations of nutrients and low temperatures of surface waters (Cruzado 1985, Estrada et al. 1985). Punta Bianca is also close to a relatively small estuary that may have increased the local concentration of nutrients and decreased the temperature of the sea water. These conditions might account for the events of intense recruitment of filamentous algae observed on this shore.

High productivity in this area might also explain the large number of limpets observed at Punta Bianca (see Fig. 1B,C). Supply of food is important for the maintenance of spatial differences in the abundance of grazers. Availability of food in the form of drift algae, for example, is known to maintain high densities of limpets on rocky shores in South Africa (Bustamante et al. 1995). In contrast, the proliferation of filamentous algae might have been responsible for the reduction in the density of limpets observed in winter at Punta Bianca (see Fig. 1C). This discrepancy might have occurred because of the different size and mode of feeding of limpets on these shores. In South Africa, limpets are large and can forage on stands of adult plants (Bustamante et al. 1995). In contrast, in the northwest Mediterranean limpets are generally small (15 $\mathrm{mm}$ on average), and they apparently forage on the microbial film and on propagules of macroalgae, but not on the adult thalli of these plants. This suggests that while limpets at Punta Bianca benefited from being in a productive area, strong bottom-up effects were not necessarily positive events for these organisms, since they were apparently unable to exploit large supplies of resources when these occurred in the form of intense recruitment of macroalgae. Further experimental investigations are necessary to test alternative models about bottom-up effects and trophic interactions on these shores on the basis of these observations. Experiments should also address whether the different species of Patella spp. can have different effects on these assemblages (e.g. Della Santina et al. 1993).

Limpets were numerically more abundant on vertical than horizontal substrata at Baratti and Punta Bianca, supporting the model that vertical substrata provide a better habitat for these grazers than flat surfaces (Garrity 1984, Williams \& Morritt 1995). In contrast, the reverse was often observed for the filamentous algae. Limpets accounted for about $38 \%$ of the differences between substrata, indicating that grazing was important in maintaining variable patterns of distribution of the filamentous algae among sites of different slope.

The effects of grazing gastropods on rocky shores are known to vary seasonally in relation to variation in recruitment of algae and/or in the foraging activity of herbivores (Hawkins 1981, Cubit 1984, Breitburg 1985). Here, although differences between seasons changed from shore to shore and in relation to slope of the substratum, there was a trend for a larger effect of limpets in treatments initiated in winter, as indicated by the response of the filamentous algae. However, because plots were monitored after $1.5 \mathrm{yr}$, those treatments initiated in winter were sampled during the summer months and the results indicated that the filamentous algae were abundant in this season. This suggested that physical stress was not as intense as initially supposed during the summer. Thus, excluding limpets in summer or winter probably made no difference in terms of long-lasting effects on assemblages. Rather, specific patterns of abundance of organisms at the time of sampling might have originated from the interactions between grazing and season observed here. This is consistent with the results of a companion study, where the effects of limpets were monitored over shorter periods (Benedetti-Cecchi et al. unpubl. data).

Whether grazers have negative or positive effects on encrusting algae is not clear. Some evidence indicates 
that by removing erect plants, herbivores indirectly enhance the survival and growth of encrusting algae which are morphologically adapted to withstand the effects of grazing (Lubchenco \& Cubit 1980, Steneck \& Dethier 1994). Other evidence suggests that herbivory may be detrimental to algal crusts, as observed for erect plants (e.g. Levings \& Garrity 1984). In the present study, there was a trend for encrusting coralline algae to be more abundant in the presence of limpets on horizontal substrata at Baratti. This might have resulted from the overgrowth of these plants by erect algae in plots from which limpets were excluded. However, the only significant effect of limpets on encrusting coralline algae was observed at Punta Bianca, and this was a negative effect. These results did not help in clarifying patterns of interactions between limpets and encrusting algae, but suggested that these interactions cannot be generalized and must be interpreted within the specific spatial and temporal context in which they occur. Again, the possibility that the 3 species of limpets present on these shores can have distinct effects on macroalgae (Della Santina et al. 1993) might explain some of this variability.

The effect of limpets on whole assemblages was generally weak and changed over space and time with no clear pattern; there was also considerable variation among replicates within any treatment. These patterns contrasted to those found in a companion study on the role of limpets in maintaining differences between mid- and low-shore assemblages in the northwest Mediterranean (Benedetti-Cecchi et al. 2000). In that study, limpets were found to account for about $20 \%$ of the differences between habitats, and this effect was consistent over space and time.

Some studies have shown that interactions between different processes occur at small scales in space and time (e.g. Kennelly \& Underwood 1993, Lively et al. 1993, Chapman \& Underwood 1998). It has been suggested that small-scale variability results from experiments with high resolution, and this is viewed as an impediment to the detection of large-scale processes (Root \& Schneider 1995, see discussion in Hewitt et al. 1998). High resolution occurs when experimental units of small size are used, a condition that may be dictated by logistical constraints. More often, however, the size of the experimental unit is chosen as a function of the particular processes being investigated and in relation to the natural history of the system. Thus, for example, the size of the experimental units used to investigate models about physical disturbance and its interactions with biological processes is usually chosen to match the size of naturally disturbed patches (Sousa 1984, Chapman \& Underwood 1998, Benedetti-Cecchi 2000). Similarly, experimental analyses on the effects of limpets on rocky shores require high resolution be- cause limpets respond to fine-scale features of the habitat. As shown in the present investigation, where interactions at relatively large spatial and temporal scales were found, high resolution does not necessarily obscure large-scale events. Increasing the extent of ecological studies while maintaining the resolution consistent with the hypotheses being tested and the biology of the system seems the best approach to investigate and understand scales of variation in ecological processes.

Although multiscale analyses on the spatial and temporal patterns of distribution of natural populations are increasing both in terrestrial and aquatic systems (Schneider 1994), and the need for large-scale experiments has been emphasized (Paine et al. 1985, Reader et al. 1994, Carpenter et al. 1995, Berlow \& Navarrete 1997), few experimental investigations have examined multiple scales of variation in ecological processes. Studies of this sort are important for a number of reasons. First, they set limits to ecological generalizations by identifying the spatial and temporal context within which ecological processes operate consistently. Second, by detecting the scale(s) at which the magnitude of ecological processes change, they increase our understanding of the causes of spatial and temporal variations in abundance of natural populations. Third, the detection of these changes is useful to identify profitable areas for further research. Studies conducted at multiple scales are therefore important for understanding the circumstances under which ecological processes can be expected to produce predictable patterns in populations and assemblages (Benedetti-Cecchi 2000, and references therein). For example, grazing was consistent across sites on any given shore in the present study, so that knowledge of the effects of limpets at a few sites could be used to predict the consequences of grazing at other sites on a particular shore. In contrast, the large variability among shores prevented scaling-up from the shore to the regional scale when examining hypotheses about the effects of limpets in the northwest Mediterranean. Although this variability poses limits to generalizations, identifying the underlying causes would provide a basis for predicting the effects of limpets on other shores. Understanding the processes that prevent generalizations can result in useful, albeit rather specific, ecological models (Benedetti-Cecchi 2000). This may be a starting point to addressing the issue of how we can move beyond the fatalistic view that natural variability makes general ecological models inaccurate and imprecise.

Acknowledgements. We sincerely thank Gee Chapman, Ross Coleman and Fiorenza Micheli for helpful comments on the manuscript. M. Menconi and I. Bertocci provided invaluable assistance with the field work. L.B.-C. wishes to thank Tony 
Underwood for providing room and facilities during a Visiting Scholarship at The Centre for Research on Ecological Impacts of Coastal Cities, University of Sydney, where the final version of this manuscript was prepared. This research was supported by the EU under Contract MAS3-CT95-0012, and by a grant from the University of Pisa.

\section{LITERATURE CITED}

Anderson MJ, Underwood AJ (1997) Effects of gastropod grazers on recruitment and succession of an estuarine assemblage: a multivariate and univariate approach. Oecologia 109:442-453

Benedetti-Cecchi L (2000) Direct and indirect interactions during succession in a midlittoral rocky shore assemblage. Ecol Monogr 70:45-72

Benedetti-Cecchi L, Cinelli F (1993) Early patterns of algal succession in a midlittoral community of the Mediterranean sea: a multifactorial experiment. J Exp Mar Biol Ecol 169:15-31

Benedetti-Cecchi L, Cinelli F (1997) Confounding in field experiments: direct and indirect artifacts due to the manipulation of limpets and macroalgae. J Exp Mar Biol Ecol 209:171-184

Benedetti-Cecchi L, Bulleri F, Cinelli F (2000) The interplay of physical and biological factors in maintaining mid-shore and low-shore assemblages on rocky coasts in the northwest Mediterranean. Oecologia 123:406-417

Berlow EL, Navarrete SA (1997) Spatial and temporal variation in rocky intertidal community organization: lessons from repeating field experiments. J Exp Mar Biol Ecol 214: 195-229

Branch GM (1981) The biology of limpets: physical factors, energy flow, and ecological interactions. Oceanogr Mar Biol Annu Rev 19:235-380

Bray JR, Curtis JT (1957) An ordination of the upland forest communities of Southern Wisconsin. Ecol Monogr 27: 325-349

Breitburg DL (1985) Development of a subtidal epibenthic community: factors affecting species composition and the mechanisms of succession. Oecologia 65:173-184

Bustamante RH, Branch GM, Eekhout S (1995) Maintenance of an exceptional intertidal grazer biomass in South Africa: subsidy by subtidal kelps. Ecology 76:2314-2329

Carpenter SR, Chisholm SW, Krebs CJ, Schindler DW, Wright R (1995) Ecosystem experiments. Science 269: 324-327

Chapman MG, Underwood AJ (1992) Foraging behaviour of marine benthic grazers. In: John DM, Hawkins SJ, Price $\mathrm{JH}$ (eds) Plant-animal interactions in the marine benthos. Systematics Association Special Volume No. 46. Clarendon Press, Oxford, p 289-317

Chapman MG, Underwood AJ (1998) Inconsistency and variation in the development of rocky intertidal algal assemblages. J Exp Mar Biol Ecol 224:265-289

Clarke KR (1993) Non-parametric multivariate analyses of changes in community structure. Aust J Ecol 18:117-143

Connell JH (1983) On the prevalence and relative importance of interspecific competition: evidence from field experiments. Am Nat 122:661-696

Cruzado A (1985) Chemistry of Mediterranean waters. In: Margalef R (ed) Western Mediterranean. Pergamon Press, Oxford, p 126-147

Cubit JD (1984) Herbivory and the seasonal abundance of algae on a high intertidal rocky shore. Ecology 65: 1904-1917
Danielson BJ (1991) Communities in a landscape: the influence of habitat heterogeneity on the interactions between species. Am Nat 138:1105-1120

Dayton PK (1971) Competition, disturbance, and community organizations: the provision and subsequent utilization of space in a rocky intertidal community. Ecol Monogr 41: 351-389

Dayton PK, Tegner MJ (1984) The importance of scale in community ecology: a kelp forest example with terrestrial analogs. In: Price PW, Slobodchikoff CN, Gaud WS (eds) A new ecology: novel approaches to interactive systems. Wiley, New York, p 457-483

Della Santina P, Sonni C, Sartoni G, Chelazzi G (1993) Food availability and diet composition in three coexisting Mediterranean limpets (Patella spp.). Mar Biol 116:87-95

Dethier MN, Duggins DO (1988) Variation in strong interactions in the intertidal zone along a geographical gradient: a Washington-Alaska comparison. Mar Ecol Prog Ser 50: 97-105

Estrada M, Vives F, Alcarez M (1985) Life and the productivity of the open sea. In: Margalef R (ed) Western Mediterranean. Pergamon Press, Oxford, p 148-197

Farrell TM (1991) Models and mechanisms of succession: an example from a rocky intertidal community. Ecol Monogr 61:95-113

Field JC, Clarke KR, Warwick RM (1982) A practical strategy for analysing multispecies distribution patterns. Mar Ecol Prog Ser 8:37-52

Gaines SD, Lubchenco J (1982) A unified approach to marine plant-herbivore interactions. II. Biogeography. Annu Rev Ecol Syst 13:111-138

Garrity SD (1984) Some adaptations of gastropods to physical stress on a tropical rocky shore. Ecology 65:559-574

Hawkins SJ (1981) The influence of season and barnacles on the algal colonization of Patella vulgata exclusion areas. J Mar Biol Assoc UK 61:1-15

Hawkins SJ, Hartnoll RG (1983) Grazing of intertidal algae by marine invertebrates. Oceanogr Mar Biol Annu Rev 21: 195-282

Hawkins SJ, Hartnoll RG, Kain JM, Norton TA (1992) Plantanimal interactions on hard substrata in the north-east Atlantic. In: John DM, Hawkins SJ, Price JH (eds) Plantanimal interactions in the marine benthos. Systematics Association Special Volume No. 46. Clarendon Press, Oxford, p 1-32

Hewitt JE, Thrush VJ, Cummings SJ, Turner SJ (1998) The effects of changing sampling scale on our ability to detect effects of large-scale processes on communities. J Exp Mar Biol Ecol 227:251-264

Huntly N (1991) Herbivores and the dynamics of communities and ecosystems. Annu Rev Ecol Syst 22:477-503

Kennelly SJ, Underwood AJ (1993) Geographic consistencies of effects of experimental physical disturbance on understorey species in sublittoral kelp forests in central New South Wales. J Exp Mar Biol Ecol 168:35-58

Kolasa J, Pickett STA (1991) Ecological heterogeneity. Springer-Verlag, New York

Levings SA, Garrity S (1984) Grazing patterns in Siphonaria gigas (Mollusca, Pulmonata) on the rocky Pacific coast of Panama. Oecologia 64:152-159

Lively CM, Raimondi PT, Delph LF (1993) Intertidal community structure: space-time interactions in the northern Gulf of California. Ecology 74:162-173

Lubchenco J, Cubit J (1980) Heteromorphic life histories of certain marine algae as adaptations to variations in herbivory. Ecology 61:676-687

Lubchenco J, Gaines SD (1981) A unified approach to marine 
plant-herbivore interactions. I. Populations and communities. Annu Rev Ecol Syst 12:405-437

Lubchenco J, Menge BA (1978) Community development and persistence in a low rocky intertidal zone. Ecol Monogr 48: 67-94

Menconi M, Benedetti-Cecchi L, Cinelli F (1999) Spatial and temporal variability in the distribution of algae and invertebrates on rocky shores in the northwest Mediterranean. J Exp Mar Biol Ecol 233:1-23

Menge BA (1992) Community regulation: under what conditions are bottom-up factors important on rocky shores? Ecology 73:755-765

Menge BA (1995) Indirect effects in marine rocky intertidal interaction webs: patterns and importance. Ecol Monogr 65:21-74

Menge BA, Sutherland JP (1987) Community regulation: variation in disturbance, competition, and predation in relation to gradients of environmental stress and recruitment. Am Nat 130:730-757

Paine RT, Castilla JC, Cancino J (1985) Perturbation and recovery patterns of starfish-dominated intertidal assemblages in Chile, New Zealand, and Washington State. Am Nat 125:679-691

Petraitis PS (1990) Direct and indirect effects of predation, herbivory and surface rugosity on mussel recruitment. Oecologia 83:405-413

Power ME (1992) Top-down and bottom-up forces in food webs: do plants have primacy? Ecology 73:733-746

Reader RJ, Wilson SD, Belcher LW, Wisheu I, Keddy PA, Tilman D, Morris EC, Grace JB, McGraw JB, Olf H, Turkington $\mathrm{R}$, Klein $\mathrm{E}$, Leung $\mathrm{Y}$, Shipley $\mathrm{B}$, van Hulst $\mathrm{R}$, Johansson ME, Nilsson C, Gurevitch J, Grigulis K, Beisner BE (1994) Plant competition in relation to neighbour biomass: an intercontinental study with Poa pratensis. Ecology 75:1753-1760

Root TL, Schneider SH (1995) Ecology and climate: research strategies and implications. Science 269:334-340

Schneider DC (1994) Quantitative ecology: spatial and temporal scaling. Academic Press, San Diego

Schoener TW (1983) Field experiment on interspecific competition. Am Nat 122:240-285

Sih A, Crowley PH, McPeek MA (1985) Predation, competition and prey communities: a review of field experiments. Annu Rev Ecol Syst 16:269-311

Sousa WP (1984) Intertidal mosaics: patch size, propagule

Editorial responsibility: Otto Kinne (Editor),

Oldendorf/Luhe, Germany availability, and spatially variable patterns of succession. Ecology 65:1918-1935

Sousa WP (1985) Disturbance and patch dynamics on rocky intertidal shores. In: Pickett STA, White PS (eds) The ecology of natural disturbance and patch dynamics. Academic Press, Orlando, p 101-124

Steneck RS, Dethier MN (1994) A functional group approach to the structure of algal-dominated communities. Oikos 69:476-498

Underwood AJ (1979) The ecology of intertidal gastropods. Adv Mar Biol 16:111-210

Underwood AJ (1985) Physical factors and biological interactions: the necessity and nature of ecological experiments. In: Moore PG, Seed R (eds) The ecology of rocky coasts. Hodder \& Stoughton, London, p 372-390

Underwood AJ (1997) Experiments in ecology: their logical design and interpretation using analysis of variance. Cambridge University Press, Cambridge

Underwood AJ, Denley EJ (1984) Paradigms, explanations and generalisations in models for the structure of intertidal communities on rocky shores. In: Strong DR, Simberloff D, Abele LG, Thistle AB (eds) Ecological communities: conceptual issues and the evidence. Princeton University Press, Princeton, p 151-180

Underwood AJ, Jernakoff P (1981) Effects of interactions between algae and grazing gastropods on the structure of a low shore intertidal algal community. Oecologia 48: 221-223

Underwood AJ, Petraitis PS (1993) Structure of intertidal assemblages in different locations: how can local processes be compared? In: Ricklefs R, Schluter D (eds) Species diversity in ecological communities. University Chicago Press, Chicago, p 38-51

Underwood AJ, Denley EJ, Moran MJ (1983) Experimental analyses of the structure and dynamics of mid-shore rocky intertidal communities in New South Wales. Oecologia 56: 202-219

Wiens JA, Stenseth NC, van Horne B, Ims RA (1993) Ecological mechanisms and landscape ecology. Oikos 66: 369-380

Williams GS, Morrit D (1995) Habitat partitioning and thermal tolerance in a tropical limpet, Cellana grata. Mar Ecol Prog Ser 124:89-103

Winer BJ, Brown DR, Michelis KM (1991) Statistical principles in experimental design, 3rd edn. McGraw-Hill, New York

Submitted: March 22, 2000; Accepted: July 27, 2000

Proofs received from author(s): December 14, 2000 